\title{
Electrification of Subsea Systems: Requirements and Challenges in Power Distribution and Conversion
}

\author{
Kaushik Rajashekara, Harish S. Krishnamoorthy, and B. Satish Naik
}

\begin{abstract}
The subsea industry has become more predominant in recent years because of the discovery of a significant number of new oil and gas fields located in deep water, a term often used to describe offshore projects located in water depths greater than 600 feet. In order to extract oil and gas, a large number of electrical systems need to be deployed at the seabed. Many of these electrical systems need high-reliability power grid and power control units located on the seabed to minimize downtime. Power system and power electronics play a major role in providing the required and reliable power to various electrical systems. But there are many challenges for deploying power components under the seabed. This paper presents the challenges and the requirements of power system components operating in subsea environment, use of power electronics for efficient transmission of power from the offshore platform or from the shore to the subsea electrical loads; variable speed drive systems; and research areas related to power electronics for subsea electrical systems.
\end{abstract}

Index Terms - Architecture, HVDC transmission, power cables, power electronics, subsea power system, under water systems.

\section{INTRODUCTION}

$\mathrm{T}$ HE term subsea refers to the exploration, drilling, and development of oil and gas fields in deep water locations. These deep-water production systems require long distance power transmission and distribution that supply electrical power to various subsea loads from the onshore generating plants. Until recently, the offshore industry preferred placing the converters and power system equipment for supplying the subsea loads on shore or on the subsea vessel at the topside of the ocean. This was mainly because it is challenging for humans to install equipment at the bottom of the ocean due to harsh environments. With advancements in robotics and other technologies such as Autonomous Underwater Vehicles (AUVs), it has become possible to install more and more equipment on the seabed [1]. There are several advantages to installing power converters and equipment close to the loads. When the electrical converters and distribution systems are placed on the seabed, it considerably reduces the cost of the power supply with similar reliability. Thus, the offshore industry is now seeing a clear trend for production equipment to be installed on the seabed [2], [3].

Manuscript received November 22, 2017.

The authors are with the Department of Electrical and Computer Engineering, University of Houston, Houston, TX - 77004, USA (e-mail: ksraja@central. uh.edu; hskrishn@central.uh.edu; sbanavat@central.uh.edu). (Corresponding author: Kaushik Rajashekara.)

Digital Object Identifier 10.24295/CPSSTPEA.2017.00024
The installation and operation of subsea electrical systems have various challenges. The pressure increases by 10 bars (about 145 PSI) for every $100 \mathrm{~m}$ depth in the ocean. The electrical systems need to be located at a water depth of about $3000 \mathrm{~m}$, which accounts for 300 bar pressure. At these depths, all the electrical components have to be designed and qualified to withstand high pressures. Additionally, sea water is a conductor and corrosive, hence proper isolation between the electrical equipment and the sea water needs to be provided. As the equipment is located at depths of up to $3,000 \mathrm{~m}$, in the event of fault, maintenance will be a challenging and will not be possible without bringing the equipment to the surface. However, bringing the equipment to surface is expensive and can result in long production outages. Hence, the reliability of the equipment for the subsea applications has to be strictly designed for more than 20 years, which implies that the mean time between failures (MTBF) should be greater than 20 years. The mean time to repair (MTTR) for subsea systems is usually very long [4].

The equipment or systems such as electric submergible pumps (ESPs) and compressors used in the production and processing of oil and gas require large amount of electrical power which is of the order of 10-15 MW. Some of the existing systems adopt supply of electric power from large gas turbine generators, which are installed on fixed or floating platforms [5]. Because of the economic and environmental constraints involved in generating large amount of power on the platform and construction of the platform itself, there is an increasing tendency to move towards supplying power to the processing loads from the conventional onshore power plants using long distance power transmission cables. This can minimize cost and maintenance involved in the platforms. However, the long step-out distances of the order of $100 \mathrm{~km}$ have several problems related to reactive power compensation and the increased power umbilical size if HVAC power transmission and distribution systems are adopted [6]-[8]. Additionally, the voltage levels used for the subsea power transmission can be typically of the order of $36 \mathrm{kV}$ to 100 $\mathrm{kV}$. Power umbilical and the corresponding power components such as connectors and the penetrators have to be rated for such voltage levels. Type of power transmission used, whether AC or $\mathrm{DC}$, could be decided by the power transmission distance based on the reactive power drawn from the source. Especially in subsea applications, each type of transmission system (AC and DC) has its own advantages and limitations which are discussed in the following sections.

Designing power electronic systems such as inverters for variable speed drives, power supplies, etc. for seabed and downhole applications is challenging. These systems have to operate 
reliably under harsh environments, be easily repairable in case of any failure, and operate at high pressure environment and high temperatures with space limitations (downhole). At present, the power converters are assembled at atmospheric pressure in steel vessels. At larger sea depths, the wall thickness of the pressure vessel increases resulting in problems of heat transfer from the power converter to sea water. This also increases the total weight. Research is being pursued by only a few organizations to develop pressure tolerant power converters and associated gate drivers to reduce weight and volume [1].

This paper discusses many of the challenges and limitations involved in the power transmission, distribution, and electronic systems. Various power transmission and distribution architectures along with the possible considerations of HVDC transmission in the subsea industry are investigated. The advantages and limitations of AC or DC distribution for subsea systems are presented. A comprehensive review on various power components such as pressure tolerant power electronics [9][12] variable speed drives, high voltage circuit breakers, power umbilical [13]-[15], wet-mate connector, and penetrators used in the transmission system is presented. The paper also presents the requirements and challenges of subsea power electronic systems and possible power converter topologies.

\section{Subsea Power Transmission and Distribution ARCHITECTURES}

The electrical power for the subsea industry is generated in two different ways, one being the offshore power generation and other is onshore generating station. In the case of offshore power generation, gas turbine driven generators are installed on the platforms that are located near the load. As the subsea loads such as ESPs and compressors are located very far from the onshore generating stations, it requires a long tieback power transmission system. Subsea industry has already started using high power high voltage AC transmission systems in order to minimize the power losses, and the reactive power due to the large capacitance of the power umbilical [16], [17]. The high voltage direct current (HVDC) transmission system in the subsea industry is being considered as an efficient power transmission solution for the long tieback subsea power systems as the number of power conductors and the reactive power consumption are minimal [18]. The transmission distance for a typical long tieback system spans from $100 \mathrm{~km}$ to $150 \mathrm{~km}$ and the distribution line distance is about $3000 \mathrm{~m}$. The transmission voltages are typically kept at higher values, of the order $36 \mathrm{kV}-100 \mathrm{kV}$ to compensate for the transmission power losses and also to reduce the reactive power consumption. However, the distribution line voltages are in general kept low of the order $3.3 \mathrm{kV}$ to $6.6 \mathrm{kV}$, to supply the individual electrical loads. The HVAC systems employ line frequency bulk transformers at the sending and receiving ends of the transmission line as well as in the distribution systems. This results in a large footprint and low power density system.

\section{A. HVAC Subsea Power Architectures}

A typical HVAC subsea power transmission and distribution

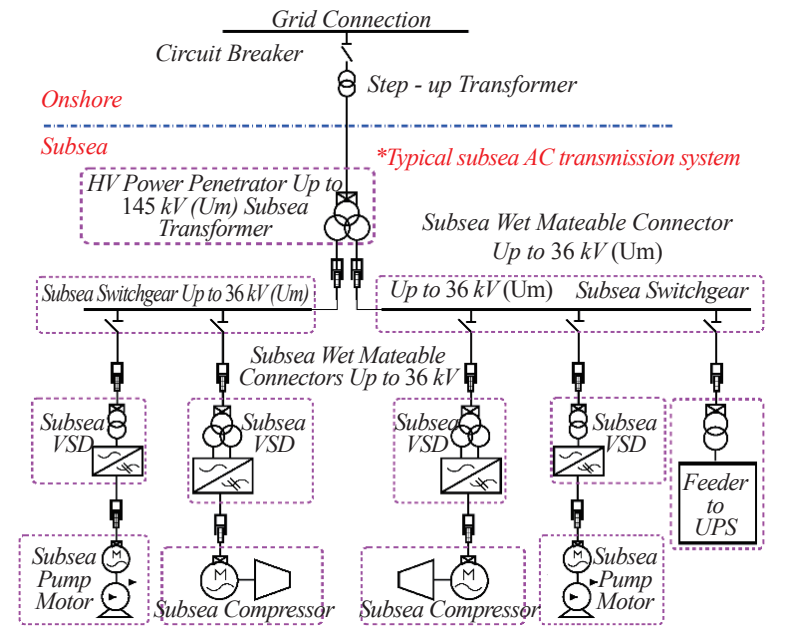

Fig. 1. Subsea power system block diagram.

architecture is shown in Fig. 1. The subsea power system components are categorized as motors, power electronic converters, step up/down transformers, switchgear, uninterruptable power supplies (UPS), subsea control modules, power management systems, etc. It also consists of compressors and pumps for artificial oil lifting. Several subsea power architectures have been reported in the literature based on the AC configuration as shown in Fig. 2(a) and Fig. 2(b). In the HVAC subsea power architecture as shown in the Fig. 2(a), power for the subsea loads is generated on-shore. In order to reduce the transmission line power losses, the generator bus voltage is boosted to a higher value by using a step up transformer. The power architecture shown employs a variable frequency drive (VFD) in the transmission system for achieving soft-start of the transmission. It may also be noted from the Fig. 2(a) that this architecture employs a large number of line frequency transformers. As a result, the overall footprint becomes large. In addition, the distribution transformer used for interfacing the transmission system to the distribution system is a large line frequency transformer. To make the distribution hub a modular structure, a series connected open end transformer based ring architecture is reported in [19] as shown in Fig. 2(b). Main advantage of this architecture is that the distribution side transformers are specifically categorized to individual loads and the entire transmission line voltage is distributed among the transformers of lower rating. The main drawback of AC transmission and distribution system is the reactive power loss. The charging current, as a result of the large capacitance, is very high especially for the subsea power umbilical. This draws large amount of reactive power from the generating station, and results in higher power losses.

\section{B. HVDC Subsea Power Architectures}

The HVDC power transmission has already gained importance in land based applications due to its advantage of enabling secure and stable operation of asynchronous interconnection of power networks that operate at different frequencies, precise and instant control of power, and zero reactive power consumption. In the conventional power transmission systems, it has 


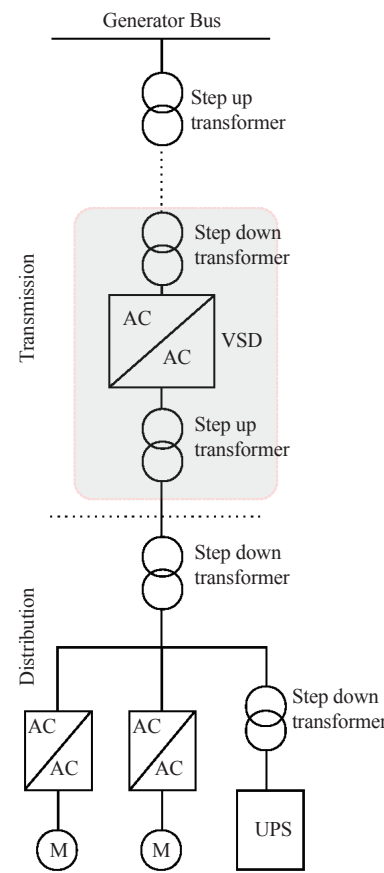

(a)

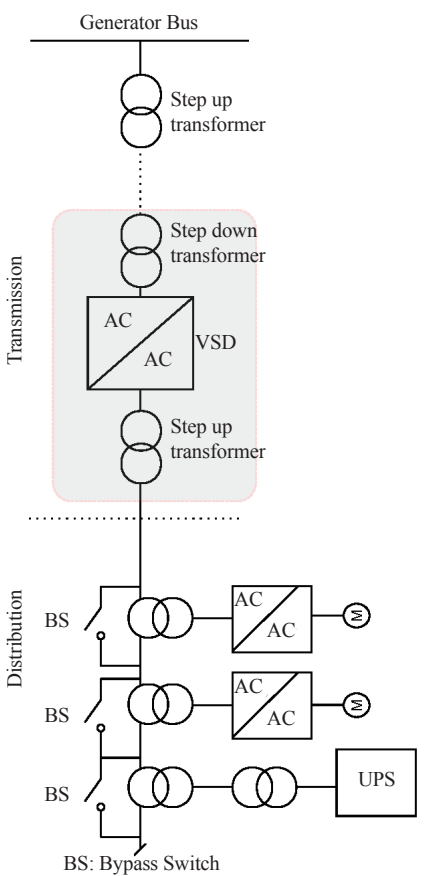

(b)

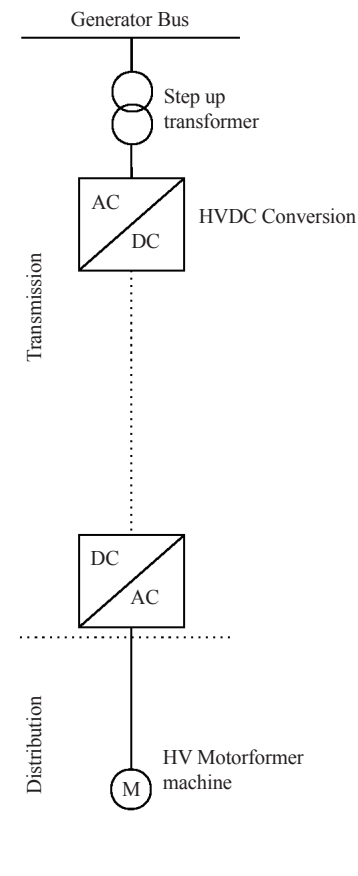

(c)

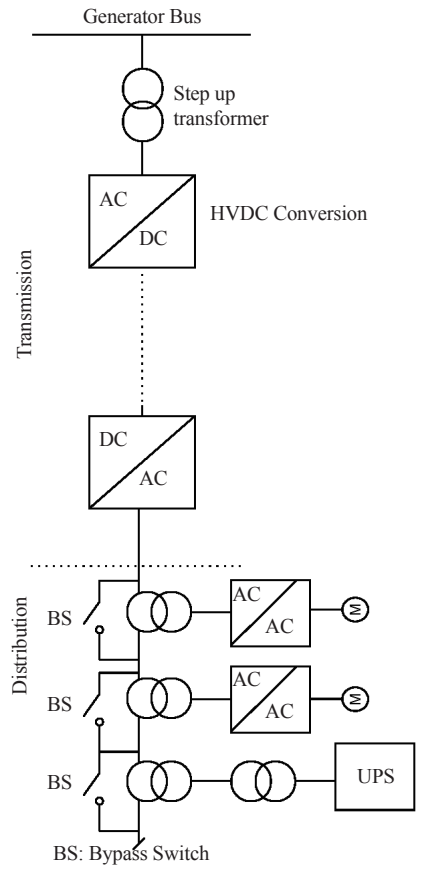

(d)

Fig. 2. Single line diagrams of various subsea power architectures, (a) HVAC subsea architecture [17], (b) Subsea HVAC ring type architecture [19], (c) Subsea HVDC power architecture of Troll A [18], (d) Subsea HVDC power architecture based on ring systems [19].

been found that the HVDC transmission overcomes HVAC systems for the transmission distances over $550 \mathrm{~km}$. However, in underground and subsea applications, a few studies have shown that the breakeven distance reduces to about $50 \mathrm{~km}$, considering reactive power compensation. The HVDC transmission shows improvements for step out distances greater than $50 \mathrm{~km}$, as cable capacitance in the subsea power umbilical is significant [20].

Due to the advantages provided by HVDC transmission, there have been a few attempts to develop HVDC architectures for subsea application. Troll A, a production platform in North Sea based on the HVDC transmission is shown in Fig. 2(c), has a step-out distance of $70 \mathrm{~km}$ and at a water depth of about $300 \mathrm{~m}$. It may be noted that the $\mathrm{AC}$ voltage generated at the platform is converted to a high voltage DC and the power is transmitted over a long distance via DC cables which has lower shunt capacitances, resulting in lower power losses. The HVDC is converted back to AC by using a power electronic converter that drives a high voltage 'motorformer' machine. The receiving end inverter is kept on a platform which is huge in size. Realizing Troll A configuration in the subsea environments will not be feasible due to its size. An attempt to further reduce the footprint and achieve modularity, a ring based HVDC structure as shown in Fig. 2(d) is been reported in [19]. This structure employs series connected open ended transformers at the distribution station, wherein each distribution transformer supplies power to the load individually. The HVAC voltage converted at the inverter (DC/AC) stage is distributed among multiple transformers and achieves modularity. In case of fault on a particular load, that particular section can be isolated by using a bypass switch which is connected across the primary winding of the transformer.

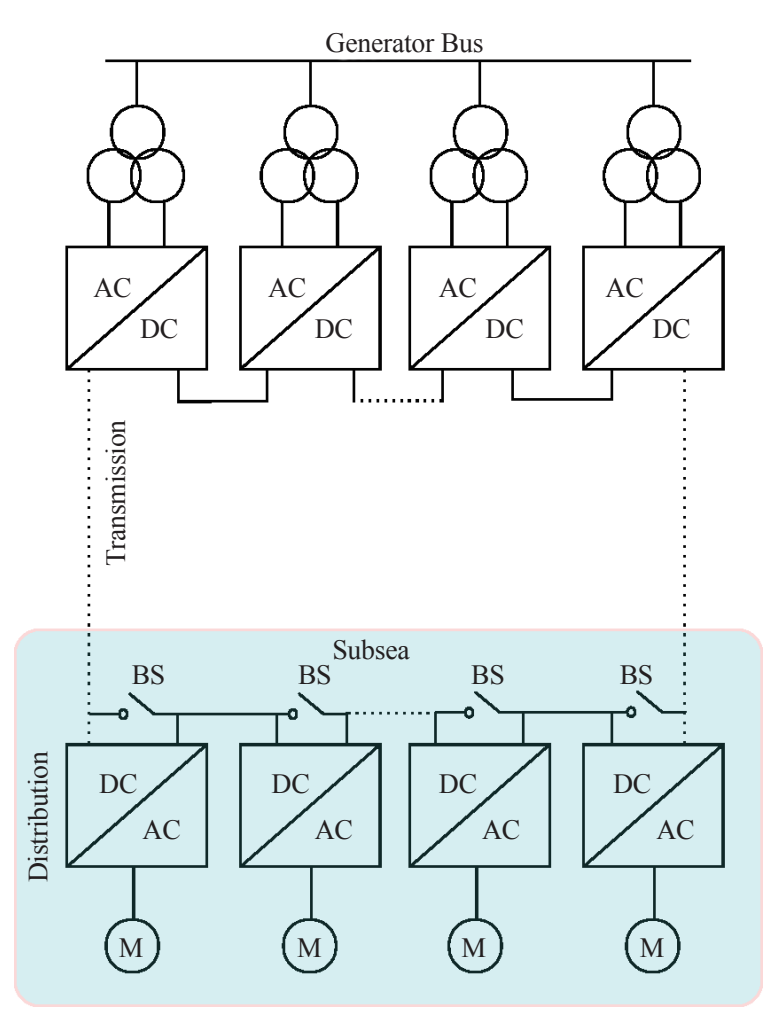

Fig. 3. Subsea modular stacked direct current structure [8].

Many subsea HVDC structures have been reviewed in [8], [19] with their merits and demerits. Authors in [8] have also proposed a HVDC subsea structure based on the modular conversion, also known as modular stacked direct current trans- 
mission (MSDC). This structure employ various multilevel converter modules which are connected in series to achieve high voltage DC operation as shown in the Fig. 3. The sending and the receiving end converter modules are operated in current controlled mode, wherein the sending end converter voltage is varied to maintain the required current and supply the load. The subsea loads, located apart in this configuration, require large number of penetrators and wet-mate connectors, which are quite expensive and highly unreliable. As a result, reliability of the system becomes poor. Hence, there is still need for further study and development of reliable and cost effective subsea power transmission and distribution architectures.

\section{Subsea Power Transmission and Distribution SYSTEMS}

In this section a brief overview and limitations of various subsea power system components are highlighted.

\section{A. High Voltage Power Umbilical}

In subsea applications, the long distance high power and high voltage transmission/distribution require strong power cables with good insulation capability. The power umbilical can be fully electric or multiplexed wherein both electrical and hydraulic lines are combined. The cross sectional view of a typical multiplexed subsea power umbilical is shown in Fig. 4 [2]. Currently, advancements in the subsea umbilical technology allow manufacture of cable for both single and three cores with bulk power transfer capability. It is also possible to produce continuous umbilical cables of lengths up to $100 \mathrm{~km}$. However, such long cables weigh in excess of 8000 tons and handling them is very difficult. This requires the manufacturing facility to have off-loading cable equipment at the site [13]. Apart from the design of subsea power umbilical, handling and maintenance also presents many challenges. The power umbilical must withstand several mechanical forces acting on it, such as force generated by its own weight, and the force due to the tidal currents. It may also be noted that, the subsea umbilical should survive due to various activities such as damage by anchors, fishing, vessel impact, and movement of the cable or seabed terrain. In general, to protect the umbilical from such events, one or two layers of metallic armor wires are provided during manufacturing.

The parametric model representation of the subsea cable in the subsea transmission differs completely from the conventional long distance transmission parametric models. Accurate model of the power umbilical is needed in order to study the effects of physical factors that come into picture in the subsea environments. The impedance will no longer be lumped, instead it will be a distributed parameter. In addition, the effects of skin and proximity phenomena become significant under such harsh environmental operations. Additionally, impedance of the power umbilical is highly frequency dependent due to the presence of large number of metallic parts within it. The subsea cable insulation coordination and its design have to consider all the above mentioned factors into account. As these cables are affected by various transient actions such as switching, sudden

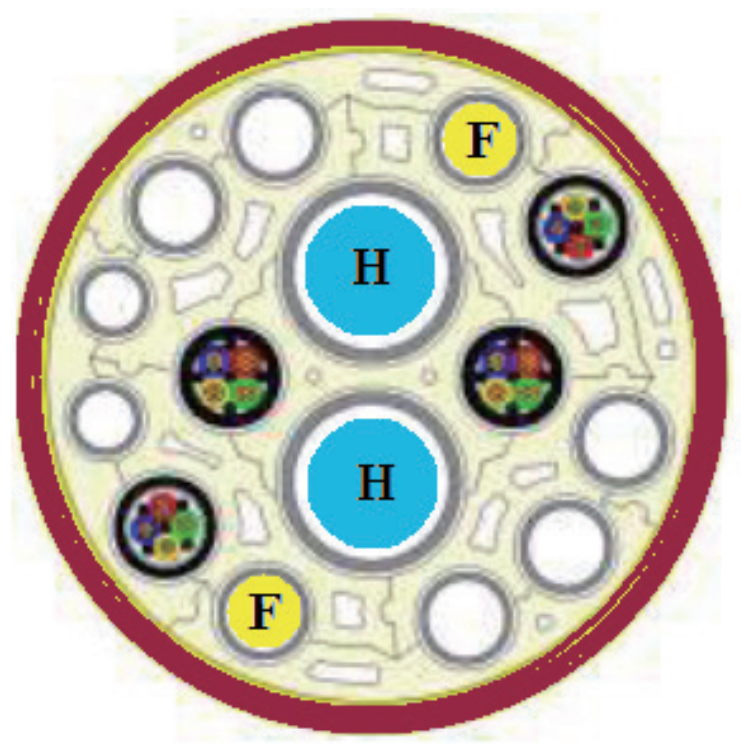

Fig. 4. Multiplexed electro-hydraulic subsea umbilical.

load change, and harmonic operation, a proper analysis for the electromagnetic transient behavioral study has to be conducted [20]. However, this study needs the exact model of the power umbilical, and it is very difficult to get the exact model. Some of the existing algorithms such as Bergeron's travelling wave model and frequency dependent model in phase domain are being considered in most of the studies.

\section{B. High Voltage Switchgear}

The HV switchgear for HVAC based subsea transmission and distribution system does not impose serious issues and challenges when compared to the HVDC transmission. The switchgear is usually kept within an enclosure and SF6 gas is used as an insulating media for providing isolation ( $3.3 \mathrm{kV}$ to $36 \mathrm{kV})$ [21]. In subsea applications, reliability (more than 20 years) is the main design criteria and using a conventionally available switchgear make the system cost effective.

Advancements in the semiconductor industry and voltage source converters make the HVDC transmission with multi terminal grid possible. Main barrier for the use of HVDC transmission is the availability of switchgear. The impedance seen by the DC source is relatively low in comparison to the AC system, hence circuit breaker should react to the fault very quickly and isolate the fault. In addition, absence of current zero crossing in the DC system imposes several challenges in the design of HVDC breaker. In order to maintain the reliability of supply system, the fault should be cleared within a few milliseconds. In this regard, numerous HVDC circuit breaker (CB) designs have been reported in the literature [21], [22]-[25]. The HVDC CBs are classified into two categories namely, solid state $\mathrm{CB}$ and the hybrid $\mathrm{CB}$. In solid state $\mathrm{CBs}$, semiconductor devices are being used, which enables fast interruption capabilities. However, series resistance of the device at higher power levels results in significant amount of power losses. The power losses are minimized by using hybrid CBs, wherein an ultra-fast mechanical 


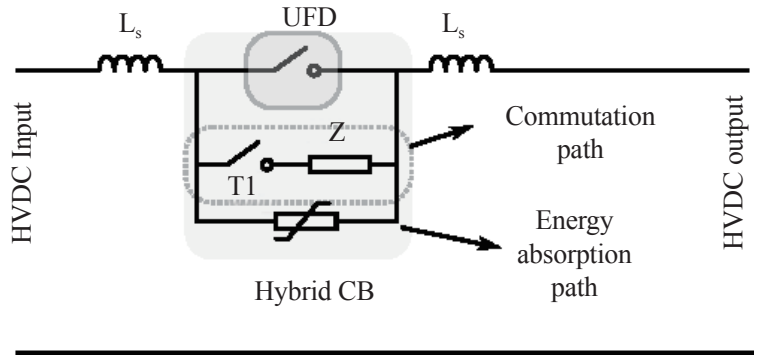

Fig. 5 Hybrid HVDC circuit breaker (Ls- refers to network inductance).

switch (UFD) in parallel with an artificial current zero crossing circuit is connected as shown in Fig. 5. Under normal condition, the load current is made to flow only through the UFD, and the parallel branch is activated only during the fault. A varistor in parallel with the HVDC CB is connected to discharge the energy stored in the network inductances. Use of varistors, especially for subsea applications, results in a large footprint. Hence, there is a scope for HVDC circuit breaker development with reduced footprint.

\section{High Voltage Power Transformer}

High voltage power transformers play an important role of step up/down of transmission and distribution voltages in the subsea power systems. Power rating of these subsea transformers may range from $500 \mathrm{kVA}$ to several MVAs. The transformers are designed to operate in the frequency range of $25 \mathrm{~Hz}$ to $75 \mathrm{~Hz}$. The subsea transformer must be designed to withstand the pressure levels imposed by sea water at depths of $3000 \mathrm{~m}$. In addition, it should be able to operate well without maintenance for longer duration of the order $>25$ years. Many leading electrical companies (ABB, SIEMENS, etc.) produce subsea transformers for high power ratings. These transformers are classified as single shell and double shell type. For pressure compensation, these transformers are filled with liquid which balances the pressure imposed by sea water with the internal pressure. A typical subsea transformer developed by SIEMENS, which is tested and qualified for $3000 \mathrm{~m}$ subsea operation is shown in Fig. 6 [26]. To maintain the reliability, it is required to continuously monitor the health of the transformer. It is also important to have an online diagnostic algorithm to identify and rectify the fault. There are many fault detection algorithms reported in the literature such as frequency response analysis (FRA), dissolved gas analysis (DGA), etc.

In HVDC subsea power transmission, DC power is converted to AC before connecting it to the load. The DC to AC conversion with present semiconductor industry enhancements can be performed in two different stages (DC-AC-AC). Initially, DC voltages are converted to high frequency $(<1 \mathrm{kHz}$ for high power) alternating voltages. Step up/down of the voltage is performed using a high frequency transformer and later it is fed to a high frequency $\mathrm{AC}$ to a line frequency $\mathrm{AC}$ converter. As this configuration employs a higher frequency transformer (solid state transformer) for the voltage transformation, footprint of the power system become smaller. However, these transformers

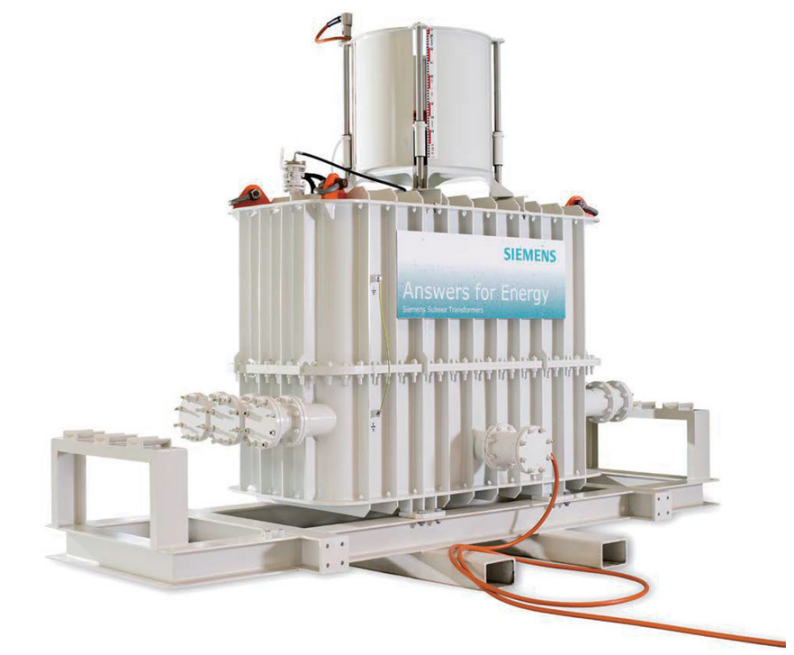

Fig. 6 Subsea power transformer (photo courtesy: SIEMENS).

have not yet made their impact in subsea applications.

\section{High Voltage Wet-Mate Connectors and Penetrators}

Wet-mate connectors and penetrators are the main limitations for the high voltage subsea power transmission. Currently, only $\mathrm{AC}$ wet-mate connectors are available up to voltage ratings of $36 \mathrm{kV}$ with a maximum current rating of $500 \mathrm{~A}\left(\mathrm{MECON}^{\mathrm{TM}}\right.$ WM-36) [27]. Similarly, AC penetrators have been reported up to a voltage of $60 \mathrm{kV}$ with $630 \mathrm{~A}$ (SpecTRON-60) current rating, however the subsea depth for this penetrator is limited to $2000 \mathrm{~m}$ [28]. Penetrators and the wet-mate connectors are the weakest points in the entire subsea power system. Hence, reliability of the supply system greatly dominated by these components. In general, these components have a designed reliability of $>25$ years under the sea.

For next generation efficient HVDC transmission and distribution of power in the subsea, wet-mate connectors and the penetrators are major barriers. Even today, subsea industry has not been able to develop these two components for the HVDC. Hence, development of HVDC wet-mate connectors and the penetrators can be considered as an evolution in the subsea industry.

\section{Power Electronics for Subsea Power Systems}

The power electronics converter technology has been considered for several subsea and downhole applications. A few of the applications are:

- Electrical drives for oil well drilling

- Wireless power transfer between modules and to minimize the replacement of batteries

- Replacing the wet mate connectors by power electronic based converters particularly in subsea dc transmission system, deploying Solid state circuit breakers, etc.

- Powering the subsea electrical systems by offshore wind energy or by ocean energy such as under water current

- Power supplies for control and monitoring

- Power converters for electrically heating of subsea pipeline 


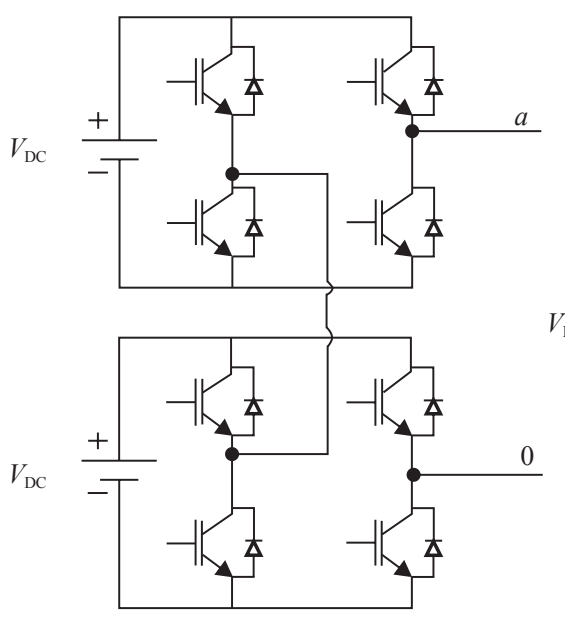

(a) $\mathrm{CHB}$

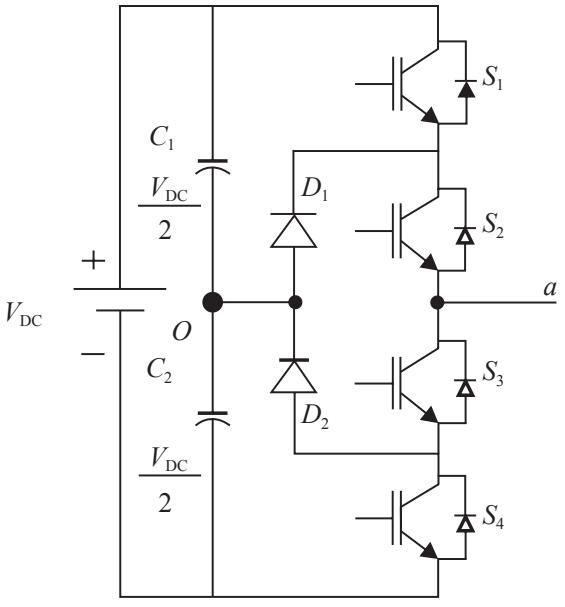

(b) NPC

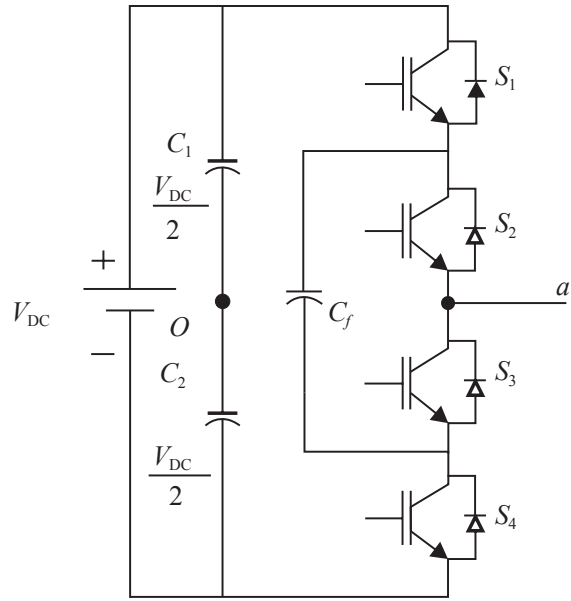

(c) FC

Fig. 7 Multilevel inverter topologies (one leg), (a) cascaded H-bridge, (b) neutral point clamped converter, (c) flying capacitor converter.

A variety of power electronic converters such as HVDC station converters, rectifiers, variable frequency drives (VFD), AC-AC converters, uninterrupted power supplies (UPS) and active front end converters, etc., are being employed in the subsea power transmission and distribution systems. This section provides an insight on the basic inverter topologies and their pressure tolerant operation in the subsea environments.

\section{A. Power Converters or VFDs}

Power converters are used for driving motors, which in turn connected to ESP and compressors that are used for boosting of oil and gas in the subsea. The power rating of the ESP and compressor systems together with the associated power converter is of the order of several MWs. Power converter or inverter is broadly classified as two-level and multilevel voltage source inverters. Two-level converters are being widely used in the industry, due to its simplicity. However, in high power and high voltage applications, the barrier for use of two-level inverter is the availability of high voltage rated devices. With the advent of multilevel inverters, it is possible to achieve high voltage operation with only existing low voltage rated devices. The conventional multilevel inverter topologies are broadly classified as neutral point clamped converters (NPC), flying capacitor (FC), and cascaded half bridge converter (CHB). The circuit diagrams of the popular multilevel converters are shown in the Fig. 7 [29]. The main limitation of these inverter topologies is that, they employ large number of components for achieving higher output voltage levels, thus affecting the reliability and increasing the complexity of the controller. These converters are being investigated for subsea power transmission and motor drives.

In modular multilevel converters (MMC), low voltage rated modules are cascaded to achieve high voltage operation. The MMC structures have a great fault tolerant capability, in terms of module failures. Faulty modules can be by-passed and system can still be operated normally but at reduced power or voltage levels. The possible application of MMC structures in the subsea HVDC transmission can be explored for future efficient subsea power architectures.

\section{B. Pressure Tolerant Power Electronics and Vessels}

As discussed in the previous sections, power electronic converters play an important role in the subsea applications. They need to operate at depths of up to $3000 \mathrm{~m}$ and at such water depth levels, pressure on the equipment may reach up to 300 bars. The power electronic converters are made to work at such conditions by enclosing them in pressure vessels that are filled with incompressible medium such as dielectric fluids. The dielectric fluid being a good insulator should also be able to have a good thermal conductivity in order to help the cooling of the power electronic system [11]. The essential properties of a dielectric fluid are high breakdown voltage, high temperature stability, nontoxicity, biodegradable, and good tolerance to moisture levels. The currently existing dielectric liquids are mineral oil, synthetic oil, silicon oil, and orgonic esters [11].

The main components of power converters are Insulated Gate Bipolar Transistor Devices (IGBT), DC link electrolytic capacitors, and the gate drivers, digital signal processor boards and sensors, which are mounted inside the pressure vessel. Existing configurations employ a one bar pressure chamber/ vessel, in which the power converter is enclosed. However, for deep water applications with pressure levels of 300 bars and high power rating of several MWs, and the wall thickness and size increases. This reduces the thermal conductivity, wherein the heat generated from the converter does not flow to the sea water effectively, resulting in poor cooling of the converter. To address the above listed issues, recently SINTEF has proposed a new concept wherein the vessel is designed for 300 bar pressure with reduced wall thickness [10], [11]. In addition, component level pressurization is being tested for power components such as IGBTs, electrolytic capacitors, and the gate drivers. Various sealing and packaging methods for two IGBT technologies, bonded IGBT and press-pack IGBTs, with the experimental test 
validation are reported in [11].

\section{Health Analytics and Fault Handling}

With the price of oil per barrel reaching its lowest value in a decade during early 2016 , the industry started taking significant steps to reduce the cost of production. A major initiative has been to improve the reliability of equipment and identify fault scenarios at an earlier stage itself so that the high costs associated with failed equipment and down-time can be reduced. This has led to increased focus on predictive fault evaluation and system health analytics for subsea and sub-surface equipment, including power converters.

Traditionally, reliability predictions have been done according to different handbook models and terms, such as mean time to failure (MTTF) and mean time between failures (MTBF). But these evaluations only consider constant failure rate and usually disregard effects due to wear out. Recently, some research findings were reported to identify more accurate methodologies for power converter reliability predictions via physics-of-failure and mission profile analysis [30]. It is important to consider the actual mission profile for power converters to more accurately predict the reliability. Moreover, with various statistical tools available at present [31], it is possible to continuously assess the health of power converters real-time using recent data from sensors and take judicious decisions. If a fault scenario is predicted, it will also be possible to complete a task at a lower system stress level and fix the equipment at the next possible opportunity, thereby reducing the chance of an unscheduled repair that can cost millions of dollars to the operators. Though such analysis have been performed in power converters for renewable energy (such as wind, solar, etc.), hardly any research activities have been reported in fossil energy industry. The extreme environments of temperature, pressure, vibrations, etc. faced by power converters in oil and gas industry make it hard and challenging to perform an accurate reliability study, since the components in such systems are many a time operated at the edge of their physical capabilities. This will require mission profile modeling of extreme environments and failure analysis of components using highly accelerated stress testing (HASS) and/ or highly accelerated life testing (HALT). These tests will provide information on the type of failure, example device breakdown, bond rupture, thermal runaway, etc. It is time to perform extreme environment reliability predictions and analytics to monitor real-time system health monitoring and diagnostics.

Another important research area is to arrive at effective fault tolerant power conversion systems including reconfiguration, redundancy, etc. thereby the system can continue to operate at a lower stress level until a task gets completed. Evaluating alternate converter strategies, such as Z-source inverter based motor drives for ESPs, can also add significant value.

\section{CONCLUSIONS}

This paper presented the main requirements and challenges of using electrical components and power electronics systems, and adapting suitable system architectures in subsea environ- ment. Various existing HVAC and HVDC subsea power architectures with their merits and demerits were discussed. This paper also addressed the critical parameters to be considered, and the required components for the future efficient and cost effective HVDC transmission and distribution systems. Various opportunities for advancement and development for electrical systems in the subsea power industry are:

- High power density power conversion systems

- Fast acting solid state circuit breakers with galvanic isolation capability

- Wet-mate connectors for high voltages

- Penetrators for high voltage systems

- Fault and pressure tolerant power electronic converters

- Health analytics and diagnostic systems

The above listed requirements and challenges for subsea applications present a wide range of opportunities for research and improvements, thus leading to efficient and more environmental-friendly subsea oil recovery system.

\section{REFERENCES}

[1] K. Rajashekara and H. Krishnamoorthy, "Power electronics for subsea systems: Challenges and opportunities," in IEEE Power Electronics and Drives Systems (PEDS) 2017, Honolulu, USA, 12-15 Dec. 2017.

[2] T. Hazel, H. H. Baerd, J. J. Legeay and J. J. Bremnes, "Taking power distribution under the sea: Design, manufacture, and assembly of a subsea electrical distribution system," IEEE Industry Applications Magazine, vol. 19, No. 5, pp. 58-67, Sept. 2013.

[3] Anthony K. Ho, "Introduction to subsea engineering for electrical engineers," 2017.

[4] T. Hazel and P. Andrea, "Supplying control power to the Asgard Subsea compression system," in Proc. Petroleum and Chemical Industry Conf. Europe (PCIC Europe), 2017.

[5] M. Yamamoto, C. F. M. Almeida, B. A. Angelico, D. Colon and M. B. C. Salles, "Integrated subsea production system: An overview on energy distribution and remote control," in Proc. IEEE Petroleum and Chemical Industry Conf. - Brasil (PCIC Brasil), 2014.

[6] C. H. Chien and R. W. G. Bucknall, "Analysis of harmonics in subsea power transmission cables used in VSC --HVDC transmission systems operating under steady-state conditions," IEEE Transactions on Power Delivery, vol. 22, No. 4, pp. 2489-2497, Oct. 2007.

[7] W. Dixon and H. Sheets, "A subsea power source for offshore oil production," in Proc. OCEAN 75 Conf, 1975.

[8] J. Song-Manguelle, M. H. Todorovic, R. K. Gupta, D. Zhang, S. Chi, L. J. Garcés, R. Datta and R. Lai, "A modular stacked DC transmission and distribution system for long distance subsea applications," IEEE Transactions on Industry Applications, vol. 50, No. 5, pp. 3512-3524, Sept. 2014.

[9] M. Hernes and R. Pittini, "Enabling pressure tolerant power electronic converters for subsea applications," in Proc. 13th European Conf. Power Electronics and Applications, 2009.

[10] S. Midttveit, M. Alford, E. Thibaut, C. Noel, D. A. B. Barbosa and S. Lanier, "Subsea electrical power standardization," in Proc. PCIC Europe 2013, 2013.

[11] R. Pittini and M. Hernes, "Pressure-tolerant power electronics for deep and ultradeep water," vol. 1, No.1, pp. 47-52, 2012.

[12] I. J. Potter, G. T. Reader, E. Clavelle, J. Kady and M. Carl, "Oxidant selection and evaluation for subsea power systems," in Proc. Int. Symp. Underwater Technology (Cat. No.00EX418), 2000.

[13] J. R. Attwood, "Cable design for subsea power links," IEEE Power Engineering Review, vol. 20, No. 9, pp. 13-14, 21, Sept. 2000.

[14] C. H. Chien, E. H. Yap, H. G. A. Martindale and R. W. G. Bucknall, "Mechanical and electrical performance analysis of high power subsea transmission cable," in Proc. UPEC 2004. 39th Int. Universities Power Engineering Conf, 2004. 
[15] R. Svoma, C. Smith and C. Conway, "Integrated condition monitoring for subsea power cable systems," in Proc. CIRED 2009 - 20th Int. Conf. and Exhibition Electricity Distribution - Part 1, 2009.

[16] H. Gedde, B. Slåtten, E. Virtanen and E. Olsen, "Ormen lange long step-out power supply," in Offshore Technology Conference, 2009.

[17] A. Grynning, S. V. Larsen and I. Skaale, "Tyrihans subsea raw seawater injection system," in Offshore Technology Conference, 2009.

[18] M. P. Bahrman and B. K. Johnson, "The ABCs of HVDC transmission technologies," IEEE Power and Energy Magazine, vol. 5, pp. 3244, 32007.

[19] X. Huang and S. T. McJunkin, "AC Ring distribution: architecture for subsea power distribution," in 29th International Conference on Ocean, Offshore and Arctic Engineering: Volume 1, 2010.

[20] S. Kolluri, P. Thummala, R. Sapkota, S. K. Panda and D. Rendusara, "Subsea power transmission cable modelling: Reactive power compensation and transient response studies," in Proc. IEEE 17th Workshop Control and Modeling for Power Electronics (COMPEL), 2016.

[21] C. M. Franck, "HVDC circuit breakers: A review identifying future research needs," IEEE Transactions on Power Delivery, vol. 26, No. 2 , pp. 998-1007, Apr. 2011

[22] K. A. Corzine, "A new-coupled-inductor circuit breaker for DC applications," IEEE Transactions on Power Electronics, vol. 32, No. 2, pp. 1411-1418, Feb. 2017.

[23] K. A. Corzine and R. W. Ashton, "A new Z-source DC circuit breaker," IEEE Transactions on Power Electronics, vol. 27, No. 6, pp. 2796-2804, Jun. 2012.

[24] D. Keshavarzi, E. Farjah and T. ghanbari, "A hybrid DC circuit breaker and fault current limiter with optional interruption capability," IEEE Transactions on Power Electronics, vol. 33, No. 3, pp. 2330-2338, 2017.

[25] C. Meyer, M. Kowal and R. W. D. Doncker, "Circuit breaker concepts for future high-power DC-applications," in Proc. Fourtieth IAS Annual Meeting. Conf. Record of the 2005 Industry Applications Conf, 2005.

[26] SIEMENS, "Subsea transformer - supporting the factory on the seabed: The next generation of subsea transfomers," 2013.

[27] M. Ghassemi, Y. Cao and Q. Chen, "A study on performance of a wetmate DC connector under overvoltages," in Proc. IEEE Electrical Insulation Conf. (EIC), 2017.

[28] SIEMENS, "SpecTRON evaluation Medium and High Voltage Electrical connector Systems," 2013.

[29] J. Rodriguez, J.-S. Lai and F. Z. Peng, "Multilevel inverters: a survey of topologies, controls, and applications," IEEE Transactions on Industrial Electronics, vol. 49, No. 4, pp. 724-738, Aug. 2002.

[30] H. Wang, K. Ma and F. Blaabjerg, "Design for reliability of power electronic systems," in Proc. IECON 2012 - 38th Annual Conf. IEEE Industrial Electronics Society, 2012.

[31] K. Ma, H. Wang and F. Blaabjerg, "New approaches to reliability assessment: Using physics-of-failure for prediction and design in power electronics systems," IEEE Power Electronics Magazine, vol. 3, No. 4, pp. 28-41, Dec. 2016

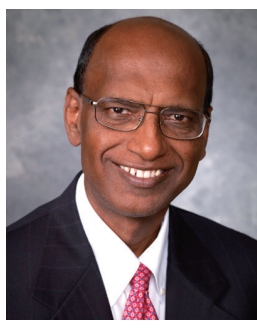

Kaushik Rajashekara received the Ph.D. degree in electrical engineering from the Indian Institute of Science, Bengaluru, India, in 1984. In 1989, he joined the Delphi Division, General Motors Corporation, Indianapolis, IN, USA, as a Staff Project Engineer. At Delphi and General Motors, he held various lead technical and managerial positions, and was a Technical Fellow and the Chief Scientist for developing electric machines, controllers, and power electronics systems for electric, hybrid, and fuel cel vehicle systems. In 2006, he joined Rolls-Royce Corporation, Indianapolis, USA, as a Chief Technologist for more electric architectures and power conversion/control technologies for more electric and hybrid aircraft systems. In August 2012, he joined as a Distinguished Professor of engineering at the University of Texas at Dallas, Dallas, TX, USA. Since September 2016, he has been a Distinguished Professor of Engineering with the University of Houston, Houston, TX. He has published more than 160 papers. He is the holder of 35 U.S. and 10 foreign patents. His research interests are in the area of power conversion and control in the areas of power electronics, electrification of transportation and renewable-energy systems. Dr. Rajashekara is a member of the National Academy of Engineering. He received the IEEE Richard Harold Kaufmann Award for outstanding contributions to the advancement of electrical systems in transportation.

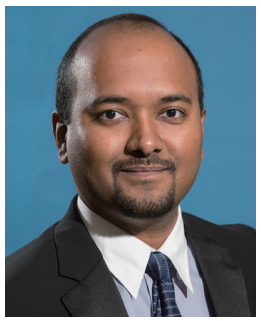

Harish S. Krishnamoorthy received his B.Tech. degree in Electrical and Electronics Engineering from National Institute of Technology (NIT), Tiruchirappalli, India and $\mathrm{Ph} . \mathrm{D}$. in Electrical and Computer Engineering, Texas A\&M University, College Station, TX. Presently, he is an Assistant Professor in the Department of Electrical and Computer Engineering at University of Houston.

Prior to this, he was an electrical engineer in the Houston Formation Evaluation (HFE) Center at Schlumberger REMS, Houston, TX, USA. He worked as an electronics engineer in the New Product Introduction team at General Electric (GE) Energy, Hyderabad, India from 2008 to 2010 . He has also worked as Research Supplemental Engineer and Hardware Engineering Intern in Ford, MI and Google Inc., CA, respectively. His research interests are in the area of power electronic converters and control, power conversion for data centers, electric vehicles, batteries, high power density converters and packaging techniques for applications in extreme environments, power supply design, modeling and control, analog circuit design and EMI/EMC, six sigma based statistical analysis for power systems, IoT applications and renewable energy systems.

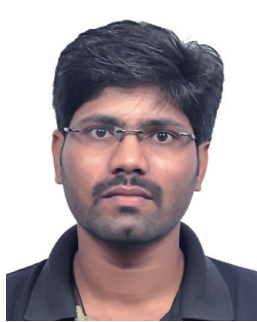

B. Satish Naik received the B.Tech degree in Electrical and Electronics Engineering from Bapatla Engineering College, Bapatla, India in 2010, and the M.E degree in Electrical Engineering from Indian Institute of Science, Bangalore, India in 2012. From 2012 to 2014, he was with the Defence Research and Development Organization, Ministry of Defence, Govt. of India, Bangalore. He finished his Ph.D. thesis in the area of Grid connected multilevel converters at the Interdisciplinary Centre for Energy Research, Indian Institute of Science, Bangalore in September 2017. Currently he is working as a Post-Doctoral Fellow at Power Electronics, Microgrids and Subsea Electrical Systems (PEMSES) Center in University of Houston. His research interests include multilevel power converters, motor drives, power converters for renewable energy conversion and power quality. 